Article

\title{
Stochastically Assessing the Financial Sustainability of Individual Accounts in the Urban Enterprise Employees' Pension Plan in China
}

\author{
Xiaohua Chen * and Zaigui Yang \\ School of Insurance \& China Institute for Actuarial Science, Central University of Finance and Economics, \\ Beijing 100081, China \\ * Correspondence: chen_xh0707@126.com; Tel.: +86-010-622-88162
}

Received: 27 May 2019; Accepted: 26 June 2019; Published: 28 June 2019

check for updates

\begin{abstract}
Various countries are paying increasing attention to the long-term financial sustainability of pension plans, and the self-balancing ability of such plans is an important index to measure their long-term financial sustainability. This paper explores the financial self-balancing ability of the individual accounts of China's urban enterprise employees' pension plan (UEEPPI). In the particularly serious scenario that the individual accounts' previous accumulated funds are zero, the bookkeeping rate and the investment return rate are considered as stochastic variables in the in-depth analysis of the self-balancing ability of individual accounts, and the effects of two different bookkeeping behaviors are compared. The results indicate that if the government adopts the fixed bookkeeping rate, the individual accounts have an excellent self-balancing ability. If the government adopts a stochastic bookkeeping rate, it can further improve the self-balancing ability of individual accounts. Sensitivity analysis finds that the increase in the wage growth rate can improve the self-balancing ability of individual accounts, but the impact of contribution rate of individual accounts and the contribution wages of recruits create uncertainty. Based on the conclusions, some policy implications are proposed.
\end{abstract}

Keywords: pension plan; individual accounts; financial sustainability; stochastic analysis

\section{Introduction}

The sustainable development of the social security system supports the sustainable development of the economy and social harmony [1]. The basic pension system is one of the essential parts of the social security system, of which financial sustainability is the core principle [2,3]. At present, many developed countries are aging societies, and the aging of the population has brought severe challenges to the sustainable development of the basic pension system [4-10]. This has become an increasing concern of governments and scholars, and its payment crisis has become a global problem.

Faced with this problem, many developed countries have established relatively complete long-term financial actuarial reporting systems for basic pensions, such as the report of "Board of Trustees of the Federal Old-Age and Survivors Insurance and Disability Insurance Trust Funds" (OASID) [11], published annually by the U.S. government and the report of "Government Actuary's Quinquennial Review of the National Insurance Fund" [12], released every five years by the British government. Although China has not yet formed an official long-term financial, actuarial reporting system for basic pensions, the Chinese government and scholars have conducted extensive research on the financial sustainability of basic pensions. These studies have helped to understand the long-term financial sustainability of China's basic pensions, to accelerate the formation of China's official long-term financial, actuarial reporting system, and to demonstrate China's experience in solving the pension crisis brought about by its aging population [13-16]. 
China has already entered the state of an aging society, and the fact that basic pensions are unsustainable has become apparent. For instance, recent statistical data show that, in 2017, China's urban employees' pension fund contributions could not meet expenditures in seven of its 31 provinces [17]. Moreover, as the aging society deepens, an increasing number of provinces will have negative pension cash flow. China's current basic pension system consists of three parts, which are the pension plan for urban enterprise employees (UEEPP), the plan for the civil servants and public sector employees, and the plan for urban and rural residents. The first two are together referred to as the "urban employees' pension plan." Among the three pension plans, UEEPP is the most developed and has the largest fund size. UEEPP began in 1951 and was formed in the document "Decision on Establishing a Unified Basic Pension System for Enterprise Employees," issued by the State Council in 1997 and completed with the document "Decision on Improving the Basic Pension System for Urban Employees," issued by the State Council in 2005. UEEPP includes two accounts: social pooling accounts and individual accounts. The UEEPP's individual accounts (UEEPPI) started with the reform of 1997, which is equivalent to the government's debts to individuals. Therefore, its future financial sustainability needs special attention from scholars and the government and is closely related to the individual accounts benefits of the contributors and the credibility of the government.

Many studies [18-21] have shown the fact that UEEPP funds are not sustainable in the future. We know that UEEPP funds include a social pooling accounts fund and an individual accounts fund. It is, then, the financial health of the pooling accounts, the individual accounts fund, or a combination of both that makes the basic pension fund unsustainable in the future. Therefore, it is necessary to study the long-term financial situation of UEEPPI and whether its financial situation has a self-balancing ability. While deeply grasping the future financial status and trend of the individual accounts fund, it can also reflect the financial status of social pooling accounts fund. Then, we can infer the specific reasons why the UEEPP is not sustainable.

Another critical issue with UEEPPI is the "empty account" of individual accounts. Since the current social pooling accounts do not have sufficient funds to pay pensions, most local governments in China have to use the accumulated funds of the individual accounts to pay the pensions that belong to the pooling accounts, which has given rise to the "empty account" problem. Moreover, in the context of an increasingly aging population, individual accounts face more risk that their funds are drawn down by the pooling accounts, which intensify the "empty account" problem. So, in the extreme case of assuming that the accumulated funds from the establishment of the individual accounts in 1977 to 2018 have been reduced to zero, how will the future financial balance of UEEPPI be established? Is it possible for UEEPPI to have a self-balancing ability? Researching extreme cases is more conducive to revealing the financial situation of individual accounts and their ability to self-balance in the future, and then to enhancing the sustainable operation of the basic pension system in China.

\section{Literature Review}

The empty accounts and the future financial status of UEEPPI directly affect whether retirees' individual accounts benefits can be distributed successfully. Chinese scholars have carried out relevant research in three categories. The first category qualitatively analyzes the causes, hazards, and solutions of the problem of the empty accounts in UEEPPI [22-26]. The second category analyzes the financial status of UEEPPI, primarily using actuarial methods. For example, Jin (2014) [27] analyzed the future dynamics of the gap between pension contributions and expenditures in UEEPPI. Yang and Shi (2016) [28] estimated the financial burden of UEEPPI in 2015. Zhang (2007) [29] and Hu and Zheng (2010) [30] focused on the future solvency of UEEPPI. Zhang (2016) [31] analyzed the adjustment strategy of UEEPPI when the payment ability of individual accounts was insufficient. The third category of research is the influence of specific parameters on the financial status of UEEPPI. For instance, Wang and Zhou (2007) [32] and Zeng et al., (2013) [33] explored the impact of inflation and deflation, delayed retirement, and other factors on the financial status of UEEPPI. 
At present, there are still few studies on the application of stochastic models to the basic pension plan problem in China. Lee and Carter (1992) [34] presented the "Lee-Carter" model for predicting mortality trends. Subsequently, Lee and Thljapurkar (1994) [35] simulated the future demographic changes in the United States with stochastic techniques, replacing the traditional population prediction schemes in the "high," "medium," and "low" scenarios. Lee and Anderson (2003) [36] believed that the stochastic simulation method could generate predictive distribution, which could explain the probability of the actuarial results. Then, stochastic technology was gradually introduced into the OAISD report of the United States in 2003. Drawing on the discussed research, Chinese scholars such as Dong et al., (2005) [37] measured the implicit debt of pension plan using interest rate and mortality as random variables. Wang and Mi (2013) [38] assumed that bookkeeping rate and wages growth rate randomly fluctuated throughout each year, and they calculated different fluctuation ranges of the pension replacement rate. Sun (2016) [39] used the binomial distribution to fit the random variable of retirement age and numerically simulated the life annuity and retirement annuity. Tian (2016) [40] conducted a random forecast of the contributions and expenditures of China's basic pension in 2013-2087 and discussed the impact of the delay in retirement on the sustainability of pensions. Zheng and Liao (2017) [41] established the basic pension contributions and expenditures forecasting model under the assumption that payment status and retirement age were random variables, and they verified the accuracy of the prediction model with Beijing data. Zhao (2018) [42] assessed the solvency sustainability of UEEPP in China by a stochastic simulation method.

Previous studies have focused on the financial status of the individual accounts in three respects; their ability to make pension payments, the financial burden, and the "empty account" problem, but they have lacked further in-depth discussion of the future financial self-balancing ability of China's UEEPPI. The self-balancing ability indicator can be used to measure the sustainability of UEEPPI's finances. This paper defines the "the excellent self-balancing ability" as UEEPPI's previous year's cumulative balance plus its return on investment for the current year remaining positive after the settlement of the pension contributions and expenditures balance for the current year during the forecast period. In other words, if the cumulative balances in each year are always positive during the forecast period, then the UEEPPI can make pension payments adequately through its self-balancing ability, which indicates UEEPPI has an excellent self-balancing ability.

The study of the self-balancing ability of UEEPPI in a random environment is closer to the real situation and can reveal its self-balancing ability accurately. Based on the previous study of pension stochastic models, considering that both the bookkeeping rate and the investment return rate are stochastic variables, under the extreme scenario of assuming that the individual accounts are "empty accounts" before the starting year of calculation, we construct the pension contributions and expenditures forecast model of the UEEPPI in the next 50 years. Moreover, we investigate the self-balancing ability of UEEPPI in the two respects of the balance of contributions and expenditures in the current year (CBCE) and of the accumulated balances. The influences on UEEPPI's self-balancing ability are compared when the government in one year adopts a fixed bookkeeping rate or a random bookkeeping rate. Thus, the structure of this paper is as follows. Section 3 establishes a forecast model of the pension contributions and expenditures of UEEPPI for the next 50 years. The section considers the bookkeeping rate and the investment return rate as random variables and uses them to randomize the established model. Section 4 is the assumption and estimation of model parameters. Section 5 first analyzes the self-balancing ability of UEEPPI under the actual fixed bookkeeping rate of the Chinese government from the perspective of the CBCE and the accumulated balances. The section then further analyzes the self-balancing ability of UEEPPI if the Chinese government is prepared to change the bookkeeping rate at some arbitrary time according to stresses on pension payments in the future and compares the $\mathrm{CBCE}$ and the accumulated balances of this stochastic bookkeeping rate with the bookkeeping rate to study the self-balancing ability of UEEPPI in depth. Finally, under the fixed bookkeeping rate, the study carries out the sensitivity analysis of the main factors affecting the 
self-balancing ability of UEEPPI to investigate the effects of these factors' changes on the self-balancing ability. Section 6 presents the conclusions and policy management implications.

\section{Forecasting Model and Its Randomization}

\subsection{Forecasting Model Construction}

The "Decision on Establishing a Unified Basic Pension System for Enterprise Employees" document, issued by the State Council in 1997, is recorded as Document 26 in 1997, and according to this document, the retirees involved in the UEEPPI are retired "middle people" and retired "new people." Therefore, to improve the accuracy of the forecast, one must respectively construct the forecasting model for the contributions and expenditures of individual pension accounts for these two types of retired people. Retired "middle people" refers to the insured who has participated in work before the implementation of Document 26 in 1997 and has retired at the time of the calculation. Retired "new people" refer to retirees who have joined the pension plan after the implementation of Document 26 in 1997.

\subsubsection{Symbolic Description of the Forecasting Model}

The symbols of the forecasting model are set as follows: The average age of recruits hired into an enterprise is $e$, which is assumed to be equal to 20 years of age. The retirement age is $r$, and the retirement ages of female workers, female cadres, and male workers are 50, 55, and 60 respectively. The number of female workers is four times that of female cadres. The ultimate survival age is $\omega$, which is assumed to be equal to 100 years of age. The contribution rate of UEEPPI is $p$, and the insured's continuous contribution rate is $c$. The annual individual accounts pension for the retired "middle people" of $x$ years of age in year $t$ is $P_{t, x}^{M}$. The number of insured aged $x$ in year $t$ is $L_{t, x}$, of which males are $L_{t, x}^{M}$ and females are $L_{t, x}^{F}$. The salary of the insured of $x$ years of age in the year $t$ is $S_{t, x}$. The growth rate of working age wages, the investment return rate, bookkeeping rate, and wages growth rate of $t$ years are $s, i_{t}, j_{t}$, and $g_{t}$ respectively. The term $z$ is the starting year of the implementation of the Document 26 in 1997, which is equal to 1997.

\subsubsection{Pension Contributions}

The pension contribution for each year during the forecast period is $C_{t}$, which is equal to the individual endowment insurance premium paid by incumbent insured, and the contribution base is the salary of the previous year. The contribution $C_{t}$ can be expressed as:

$$
C_{t}=p c \sum_{x=e}^{r-1} L_{t, x} S_{t-1, x-1}
$$

where $S_{t-1, x-1}$ refers to the previous year's salary of $x$-year-old insureds, which is the base of their contribution. The salary of the previous year $S_{t-1, x-1}$ can be further expressed as $S_{t-1, x-1}=$ $(1+s)^{x-e-1} \cdot S_{t-1, e} \cdot S_{t-1, e}$ can also be further expressed as $S_{t-1, e}=\left(1+g_{t-2}\right) \cdot S_{t-2, e} /(1+s)$.

\subsubsection{Pension Expenditures}

To improve the accuracy of the prediction model, we divide the forecast period into sections, and the prediction model of pension expenditures are constructed separately.

Pension Expenditure in Year $t \in[2019, z+r-e]$

During the forecast period, both male and female insureds are not retired "new people"; UEEPPI only need to pay individual accounts pensions of the retired "middle people." In the year $t$, the age range of the retired "middle people" is $[r, r+t-z-1]$. The UEEPPI pays individual accounts pensions that the insureds deserve within the number of months after their retirement. The term $m_{r}$ refers to the number of months for which the insureds should receive individual accounts pensions at the retirement 
age of $r$. To simplify the calculation, we assume that after the UEEPPI has paid the individual accounts pensions for an integer number of years, the remaining months are no longer paid by the individual accounts but by the social pooling accounts. Let $M_{r}^{\text {int }}$ denote the integer part of $m_{r} / 12$. Therefore, the UEEPPI only pays individual accounts pensions of the insureds whose age range is $r \sim r+M_{r}^{\text {int }}-1$ years old.

The UEEPPI payment for individual accounts pensions of retired "middle people" is $P_{t}{ }^{M}$, expressed as:

$$
P_{t}^{M}=\sum_{x=r}^{r+M_{r}^{\mathrm{int}}-1} L_{t, x} P_{t, x}^{M}
$$

where $P_{t, x}^{M}$ is the annual individual accounts pensions for retired "middle people" who are $x$ years of age in year $t$, which is equal to the cumulative amount of pension in the retirees' individual accounts divided by the number of years for which these are due. Yang and $\mathrm{Xu}$ (2017) [43] found the derivation principle of $P_{t, x^{\prime}}^{M}$ which can be further derived as:

$$
P_{t, x}^{M}=P_{t-(x-r), r}^{M}=\frac{12}{m_{r}} c \frac{p S_{1996, x-(t-1996)}}{1+g_{1995}} \sum_{n=0}^{t-(x-r)-z-1}\left[\prod_{k=0}^{n}\left(1+g_{1995+k}\right) \cdot \prod_{h=n}^{t-(x-r)-z-1}\left(1+j_{1997+h}\right)\right]
$$

Therefore, the term $P_{t}^{\text {life }}$ refers to the pensions paid to the insureds who are still alive during this forecast period, which is equal to Formula (2) and can also be expressed as:

$$
P_{t}^{l i f e}=P_{t}^{M}
$$

Pension Expenditure in Year $t \in\left[z+r-e+1, z+r-e+M_{r}^{\text {int }}\right]$

Retired "new people" appear during the period; therefore, the UEEPPI needs to pay the individual accounts pensions of retired "middle people" and "new people" at the same time. The individual accounts pensions for retired "new people" do not exceed the number of months that should be paid, but the number of people who need to pay for retired "new people" is increasing yearly. The age range

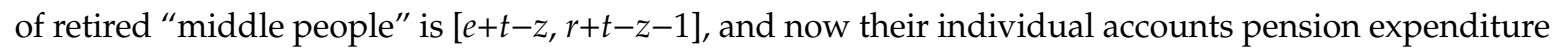
can be expressed as:

$$
P_{t}^{M}=\sum_{x=e+t-z}^{r+M_{r}^{\mathrm{int}}-1} L_{t, x} P_{t, x}^{M}
$$

The expression $P_{t, x}^{M}$ is consistent with that of the year $t \in[2019, z+r-e]$. The retirement age of retired "new people" is $[r, e+t-z-1]$, and the individual accounts pension expenditure for them is $P_{t}{ }^{N}$, expressed as:

$$
P_{t}^{N}=\sum_{x=r}^{e+t-z-1} L_{t, x} P_{t, x}^{N}
$$

where $P_{t, x}^{N}$ is the annual individual accounts pension for retired "new people" of $x$ years of age in year $t$, and the derivation principle of $P_{t, x}^{N}$ is the same as $P_{t, x}^{M}$ specifically expressed as:

$$
\begin{gathered}
P_{t+q, r+q}^{N}=P_{t, r}^{N}=\frac{12}{m_{r}} c \frac{p S_{t-(r-e)-1, e-1}}{1+g_{t-(r-e)-2}} \sum_{n=0}^{r-e-1}\left[\prod_{k=0}^{n}\left(1+g_{t-(r-e)-2+k}\right) \prod_{h=n}^{r-e-1}\left(1+j_{t-(r-e)+h}\right)\right] \\
q=1,2, \ldots, \omega-r
\end{gathered}
$$


Thus, the UEEPPI payment for the pensions of the insureds who are still alive during the forecast period now can be expressed as:

$$
P_{t}^{\text {life }}=P_{t}^{M}+P_{t}^{N}
$$

Pension Expenditure in Year $t \in\left[z+r-e+M_{r}^{\text {int }}+1,2069\right]$

During the forecast period, the UEEPPI also needs to pay the individual accounts pensions of retired "middle people" and "new people," where the number of months of pension payments for retired "new people" exceeds the number of months that should be paid. The construction rule for the individual accounts pension expenditure formula $P_{t}{ }^{M}$ for retired "middle people" during the period is also consistent with that in year $t \in[2019, z+r-e]$. The individual accounts pension expenditure for retired "new people" is now as follows:

$$
P_{t}^{N}=\sum_{x=r}^{r+M_{r}^{\mathrm{int}}-1} L_{t, x} P_{t, x}^{N}
$$

where the construction rule of the formula $P_{t, x}^{N}$ is consistent with that in year $t \in\left[z+r-e+1, z+r-e+M_{r}^{\text {int }}\right]$. During the forecast period, the individual accounts pension expenditure for the insureds who survive is the same as Formula (8).

\section{Death Refund in Each Year of the Forecast Period}

If the insureds die during their working period or the regulated individual accounts pension payment months, the government needs to distribute the residual of the individual accounts pension at the time of insureds' deaths to their legal heirs. The document of "Decision on Improving the Basic Pension System for Urban Employees," issued by the State Council in 2005, was recorded as Document 38 in 2005. The residual refund of individual accounts pension is $P_{t}^{\text {death }}$, according to Document 38 in 2005, which includes the residual refund of individual accounts paid to insured employees and retirees when they die. This condition can be expressed as follows:

$$
P_{t}^{\text {death }}=c p \sum_{x=e}^{r-1} S_{t-1, x-1} \sum_{k=1}^{x-e+1}\left(\frac{1+g_{t-1}}{1+j_{t}} \prod_{n=1}^{k} \frac{1+j_{t-n+1}}{1+g_{t-n}}\right) \cdot D_{t, x}+\sum_{x=r}^{r+M_{r}^{\text {int }}-1}\left(\frac{m}{12}-x+r-1\right) \cdot P_{t, x} \cdot D_{t, x}
$$

where $D_{t, x}$ refers to the number of deaths of $x$-year-old insureds in year $t$. The first item on the right side of the Formula (10) is the cumulative amount of individual accounts premium paid by insured employees before their death. The second item is the individual accounts pension that the insured retirees have not yet received when they die within the number of months in which the individual accounts pension should be paid. The UEEPPI reform began in 1997; thus, $t-n+1 \geq 1997$.

\subsubsection{Current Balance of Contribution and Expenditure (CBCE) and Accumulated Balance}

There are two critical indicators for measuring the future financial self-balancing ability of UEEPPI: current balance of contributions and expenditures (CBCE) and accumulated balance. The CBCE is equal to the pension contributions minus pension expenditures of the individual accounts for the current year. Then, the formula of $\mathrm{CBCE}$ can be expressed as:

$$
C B C E_{t}=C_{t}-P_{t}^{\text {life }}-P_{t}^{\text {death }}
$$

The accumulated balance of UEEPPI is $A B_{t}$, which we can calculate as follows: If the accumulated balance in the previous year is positive, the accumulated balance for the current year is the accumulated balance of the previous year $\times(1+$ investment return rate $)+B_{t}$; if the accumulated balance of the 
previous year is negative, the accumulated balance for the current year is the accumulated balance of the previous year $+B_{t}$. Thus, the formula of $A B_{t}$ can be expressed as:

$$
A B_{t}= \begin{cases}A B_{t-1} \cdot\left(1+i_{t}\right)+B_{t}, & A B_{t-1}>0 \\ A B_{t-1}+B_{t}, & A B_{t-1} \leq 0\end{cases}
$$

\subsection{Randomization of the Forecasting Model}

\subsubsection{Stochastic Bookkeeping Rate}

The General Office of the Ministry of Human Resources and Social Security and the General Office of the Ministry of Finance in China have published the bookkeeping rate for UEEPPI annually since 2016. The bookkeeping rate has only been published for three years; therefore, its actual fluctuation is not as frequent as the market interest rate. Assuming that $j_{t}$ obeys the lognormal distribution $\ln \left(u, \sigma^{2}\right)$, and because its actual fluctuation is relatively flat, it is assumed that $j_{t}$ obeys the same lognormal distribution during the forecast period.

\subsubsection{Stochastic Investment Return Rate}

If the accumulated balance of individual accounts pensions is positive, it will be invested in the securities market. Because of the large fluctuation of investment returns, the Vasicek model is used to randomize the return rate on investment. Vasicek (1997) [44] used stochastic differential equations to characterize instantaneous interest rates, which is one of the widely-used, classic models of the term structure of interest rates. Xie and $\mathrm{Wu}$ (2002) [45] and Zhao et al., (2008) [46] showed that the Vasicek model can accurately fit the fluctuation behavior of the Chinese interest rate market. In the Vasicek model, the interest rate term satisfies the mean recovery process under the risk-neutral assumption, and the process of change is as follows:

$$
d i_{t}=a\left(\bar{i}-i_{t}\right) d t+\sigma d W_{t}
$$

where $i_{t}$ refers to the risk-free interest rate at time $t ; \bar{i}$ refers to the long-term average of interest rates; $a$ is the speed at which $i_{t}$ returns to $\bar{i} ; \sigma$ refers to instantaneous volatility of interest rate at time $t ; W_{t}$ is the standard Brownian motion. By the characteristics of Brownian motion, we know that $E\left(d i_{t}\right)=a\left(\bar{i}-i_{t}\right) d t$ and $D\left(d i_{t}\right)=\sigma^{2}$.

Based on the method (Brennan \& Schwartz, 1982) and (Sanders \& Unal, 1988) $[47,48]$ ), the discretization model of the form is obtained:

$$
i_{t}-i_{t-1}=a\left(\bar{i}-i_{t-1}\right)+\sigma\left(W_{t}-W_{t-1}\right)
$$

Let $y_{t}=i_{t}-i_{t-1}, \alpha=a \bar{i}, \beta=-a$ and $\varepsilon_{t}=\sigma\left(W_{t}-W_{t-1}\right)$, then the above Formula (14) can be written as:

$$
y_{t}=\alpha+\beta i_{t-1}+\varepsilon_{t}
$$

It is known that $E\left(\varepsilon_{t}\right)=0$ and $E\left(\varepsilon_{t}^{2}\right)=\sigma^{2}$.

\section{Parameters Estimation and Assumptions for the Forecasting Model}

\subsection{Estimation of Stochastic Bookkeeping Rate}

As of the end of May 2019, the General Office of the Ministry of Human Resources and Social Security and the General Office of the Ministry of Finance in China (referred to as the "Government") only announced the bookkeeping rates of UEEPPI for 2016-2018, making the available samples very small. Therefore, based on the experience of Wang and Mi (2013) [38], the one-year interest rate of bank deposits on the website of the People's Bank of China was selected as the sample to estimate 
the parameters of the lognormal distribution with a maximum likelihood method, and the estimated results were $u \approx-3.283$ and $\sigma^{2} \approx 0.356$. The distribution of 10,000 random numbers with the estimated random bookkeeping rate is shown in Figure 1. We see that most are distributed within $10 \%$, which is in line with China's reality.

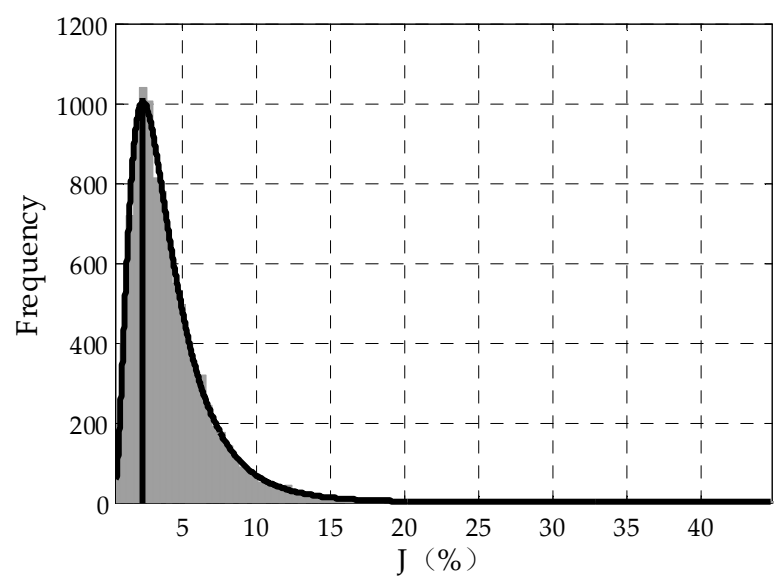

Figure 1. The distribution of the estimated random bookkeeping rates.

\subsection{Estimation of Stochastic Investment Return Rate}

The data of one-month interbank pledged weighted repo interest rates were used as the sample of the investment return rate of UEEPPI fund. The sample data were derived from a total of 996 daily trading observations recorded by the database platform of "wind" in Chinese from 4 January 2015 to 28 December 2018. Equation (15) is estimated by the least squares method. The heteroscedasticity test is performed using the White test with a statistic of 27.445 and a $p$-value of less than 0.001 . For the heteroscedasticity, the method of replacing the OLS estimated value with the heteroscedasticity consensus estimated value of the standard error of White's OLS estimator is adopted. The estimated results are shown in Table 1.

Table 1. The Estimation Result of Vasicek Model Parameters.

\begin{tabular}{ccccc}
\hline Parameter & Estimated Value & Standard Deviation & $\boldsymbol{t}$-Value & $p$-Value \\
\hline$\alpha$ & 0.138875 & 0.040655 & 3.415962 & 0.0007 \\
$\beta$ & -0.037171 & 0.011789 & -3.153048 & 0.0017 \\
\hline
\end{tabular}

According to the formula $\hat{\sigma}^{2}=\frac{\sum_{i=1}^{n} \hat{\varepsilon}^{2} i}{n-2}$, we can obtain the estimated value of $\sigma$, where $\sum_{i=1}^{n} \hat{\varepsilon}_{i}^{2}$ is equal to 60.521420 . Combining the relationships of $\alpha$ and $\bar{i}, \beta$ and $a$, we know that $a=0.037171, \bar{i}=3.736111$, $\sigma^{2}=0.060948$, and $\sigma=0.246877$. Thus, the discretized Vasicek model of Formula (14) is fitted:

$$
i_{t}=0.138875+0.962829 i_{t-1}+0.246877 d W_{t}
$$

The starting value of $i_{0}$ is $3.7769 \%$ of the mean value of the 2018 sample. According to the iteration Formula (16), the distribution of the return rate on investment in 2019 and the following years of the forecast period can be deduced. The distribution of 10,000 random numbers of the return rate on investment $i_{1}$ in 2019 and $i_{50}$ in 2069 at the end of the forecast period is shown in Figure 2. 

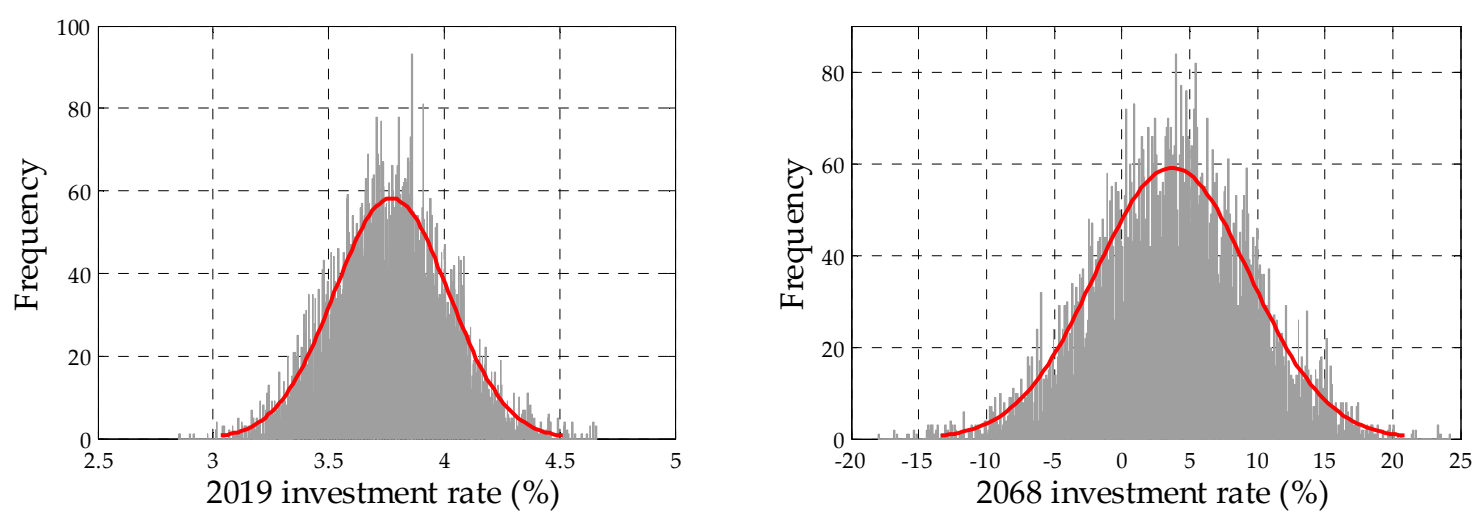

Figure 2. Distribution of stochastic investment rate for the forecast starting and ending years.

\subsection{Projection of China's Urban Population Structure}

The "cohort element method" is used to predict China's urban population structure by age and gender. The required parameters are the initial population structure, the total annual fertility rate, the annual fertility rate of women of childbearing age, the sex ratio at birth, the life table, the national urban population, and the proportion of migrants by age and gender.

1. The initial population structure: According to the China Population and Employment Statistics Yearbook 2018, the sample distribution of urban age-sex population in 2017 is discernable. We divided it by the sampling ratio to get the actual urban population distribution by age and sex in 2017 and use this value as the initial population structure.

2. Total annual fertility rate and the fertility rate of women of childbearing age: If the average fertility rate of $x$-year-old women of childbearing age in year $t$ is $f_{t, x}$ and the total fertility rate is $T F R_{t}$, then TFR $R_{t}=\sum_{x=15}^{49} f_{t, x}$. The standardized fertility coefficient is $h_{t, x}$, which is equal to $f_{t, x} / T F R_{t}$. According to the relevant China Population and Employment Statistics Yearbook, the total annual fertility rate and the average fertility rate of urban women of childbearing age from 2000 to 2017 is obtained. Then $h_{t, x}$ in each year from 2000 to 2017 can be calculated, and their average is the standardized average fertility coefficient $h_{x}$. The total fertility rate in the forecast period from 2018 to 2069 is output by the PADIS-INT population forecasting software. Therefore, the fertility rate of $x$-year-old women of childbearing age from 2018 to 2069 can be calculated by the formula $f_{t, x}=T F R_{t} \cdot h_{x}$.

3. The annual sex ratio at birth and life table: The two parameters are also output by PADIS-INT, and Zheng et al., (2014) [49] found that the "Far East" life table was more in line with the Chinese population; therefore, the "Far East" life table of PADIS-INT form 2018-2069 was chosen.

4. The national urban population: This term is equal to the total population of China multiplied by the proportion of the urban population. Although the generosity of pension schemes and contributions can affect the migration between countries [50,51], which may further affect the urbanization process, from the current situation in China, the annual net migration accounted for a very small proportion of China's total population. According to the National Bureau of Statistics of China, the net migration in China in 2017 was -1.62 million, while the total population in China in 2017 was 1390.08 million, the proportion of net migration to the total population was $0.12 \%$. Therefore, the international migration in China has little impact on its migration between rural and urban areas, and we temporarily ignore the impact of international migration on the total population and the proportion of the urban population of China. The total population of China in 2018-2069 is derived from the result of PADIS-INT's default parameters for the Chinese scenario. According to China Statistical Yearbook 2018, the proportion of the urban population from 1980 to 2017 can be determined. Based on this sample, we can predict the proportion of the urban population from 2018 to 2069 with the ARIMA $(1,2,0)$ model. In the forecast results, $80 \%$ of the 
urban population is taken as the proportion of the urban population for the year in which the proportion of the urban population exceeds $80 \%$ [52].

5. The proportion of migrants by age and gender: We assumed that the proportion of migrants at each age is the same as the corresponding age proportion of the sample distribution in the urban population by age and gender in 2017 and the proportion of men and women is the same.

Finally, MATLAB software was used to program population prediction using the "cohort element method," and then we obtained China's urban population structure by age and gender in 2018-2069.

\subsection{The Number of Insureds of Each Year in the Forecast Period}

Based on the results for China's urban population structure by age and gender in 2018-2069, we can determine the number of insureds. The labor participation rate is $R_{l}$. The coverage rate of the basic pension plan for urban employees is $R_{c}$, and the proportion of enterprises in the number of on-the-job workers insured by enterprises and governments is $R_{j}$. The proportion of enterprises in the number of retirees insured by enterprises and governments is $R_{r}$. Thus, the number of insured on-the-job workers of $x$ years of age in year $t$ is equal to the number in the urban population at the corresponding age in year $t$ multiplied by $R_{l} \times R_{c} \times R_{j}$. In the same way, the number of $x$-year-old insured retirees in year $t$ is equal to the number in the urban population at the corresponding age in year $t$ multiplied by $R_{l} \times R_{c} \times R_{r}$.

1. $R_{l}$ : According to China Labor Statistics Yearbook 2018, the average of registered unemployment rate from 1978 to 2017 is $3.43 \%$; thus, the labor participation rate is $96.57 \%$.

2. $R_{c}$ : According to "Statistical Bulletin on the Development of Human Resources and Social Security in 2015", the coverage rate of basic pension plan was about 85\% in 2015. The report of the 19th National Congress of the Communist Party of China proposed to build a social security system covering the entire population. Considering the existence of flexible employment population, we assume that the coverage rate can reach $95 \%$ in 2025 and the coverage rate increases from $85 \%$ in 2015 to $95 \%$ in 2025 at a rate of one percentage point per year, and then remains unchanged at $95 \%$ in the next years.

3. $R_{j}$ and $R_{r}$ : According to China Human Resources and Social Security Yearbook 2017, We calculated the value of $R_{j}$ from 1990 to 2016 , and took the average of the value of $94.11 \%$ as $R_{j}$ annually during the forecast period. In the same way, the average value of $R_{r}$ is $95.08 \%$.

\subsection{Estimation of Growth Rate of Working Age Wages}

The average contribution wages of the insured employees is equal to the sum of the contribution wages of the insureds of all ages divided by the total number of the insureds. The contribution wages of the insured who is $x$ years old is equal to the contribution wages of the insured who is $x-1$ years old multiplied by $(1+s)$ during the same year, and the insureds include male insureds, female workers, and female cadres. Therefore, Formula (17) can be obtained by the above three conditions, and its specific derivation process was referred to Yang and Shi (2016) [28]. The growth rate of working age wages can be estimated by Formula (17):

$$
{\overline{S^{\prime}}}_{S_{2017}}=\left\{\begin{array}{l}
l_{20 / w}+l_{21 / w}(1+s)+\cdots+l_{49 / w}(1+s)^{29} \\
+\left(\frac{1}{5} l_{50 / w}^{F}+l_{50 / w}^{M}\right)(1+s)^{30}+\left(\frac{1}{5} l_{51 / w}^{F}+l_{51 / w}^{M}\right)(1+s)^{31}+\cdots+\left(\frac{1}{5} l_{54 / w}^{F}+l_{54 / w}^{M}\right)(1+s)^{34} \\
+l_{55 / w}^{M}(1+s)^{35}+l_{56 / w}^{M}(1+s)^{36}+\cdots+l_{59 / w}^{M}(1+s)^{39}
\end{array}\right\}
$$

where ${\overline{S^{\prime}}}_{2017}$ refers to average contribution wages in the year 2017. The term $S_{2017,20}$ refers to contribution wages of recruits. The term $l_{x / w}$ refers to the proportion of on-the-job workers of $x$ years of age in the total number of on-the-job workers, $l_{x / w}^{F}$ and $l_{x / w}^{M}$ refer to the corresponding proportion of women and men, respectively. 
${\overline{S^{\prime}}}_{2017}$ : Firstly, according to the China Population and Employment Statistics Yearbook 2018, we know the number of employees and average wages of urban nonprivate units and urban private units in 2017, respectively. The average wages of employees in full-caliber urban units can be derived by weighted averages of urban nonprivate units and urban private units, which is about CNY 58,258 in 2017. In the same way, the average wages of employees in full-scale urban units in 2016 is about CNY 54,297. Secondly, according to the China Labor Statistics Yearbook 2018, we know the expenditures of the UEEPP fund and the number of enterprise retirees in 2017; then, we can calculate the average annual pension of enterprise retirees, which is about CNY 30,169. The average annual pension divides by the average wages of the full-caliber urban units in 2016 and continues to divide by the official pension replacement rate of enterprise retirees of $67.50 \%$ [53], and the result is about $82.32 \%$. Finally, we multiply the result by the average wages of the full-caliber urban units in 2017 to get $\overline{S^{\prime}} 2017$, which is about CNY 47,958.

$S_{2017,20}$ : According to the "2018 China University Student Employment Report" published by the Maxwell Institute, the annual salary of 2017 graduates at higher vocational colleges is CNY 46,320. Since the recruits have a probationary period during which the initial salary is lower, we assumed that the actual contribution wages of the recruits account for about $80 \%$ of their annual salary, then $S_{2017,20}$ is equal to CNY 37,056 .

Assuming that the distribution of insured on-the-job workers by age and gender is the same as that of China's urban population in 2017, $l_{x / w}, l_{x / w^{\prime}}^{F}$ and $l_{x / w}^{M}$ can be derived, leading to the estimate that $s$ is about $1.442 \%$ by Formula (17).

\subsection{Assumption of Other Parameters}

1. The contribution rate of UEEPPI ( $p)$ : According to Document 38 in 2005, the contribution rate of UEEPPI is set at $8 \%$.

2. The wages growth rate $\left(g_{t}\right)$ : The wages growth rate in 2017 and before is consistent with the average wages index of urban unit employees for the corresponding year from the China Labor Statistics Yearbook. Referring to the experience of Yang and Shi (2016) [28], we can set the wages growth rate in the following years, and the rate is set at 7.7\% from 2018 to 2020, at $6.6 \%$ from 2021 to 2025 , at $5.7 \%$ from 2026 to 2030 , and at $4.8 \%$ thereafter.

3. The continuous contribution rate (c): Considering that some insureds interrupt the contribution for UEEPPI every year, the continuous contribution rate is set at $85 \%$ by using Beijing's historical data.

4. The $m_{r}$ : From the above, there are three retirement ages for insureds, which are 50, 55, and 60 years old. According to the Document 38 in 2005, we know that $m_{50}=195, m_{55}=170$, and $m_{60}=139$.

\section{Self-Balancing Ability Analysis of UEEPPI}

\subsection{UEEPPI's Self-Balancing Ability under Fixed Bookkeeping Rate}

Currently, the Chinese government's actual bookkeeping behavior is to publish the bookkeeping rate for UEEPPI annually. The act of keeping the bookkeeping rate at a fixed value for one year can be recorded as the behavior of the fixed bookkeeping rate and be taken as the baseline scenario. In order to accurately correspond to the current behavior of the government in publishing the bookkeeping rate for UEEPPI once a year, we take the average of the stochastic bookkeeping rate for each year as its fixed bookkeeping rate for the corresponding year.

\subsubsection{UEEPPI's CBCE under a Fixed Bookkeeping Rate}

From the perspective of the CBCE, we can analyze the self-balancing ability of UEEPPI under a fixed bookkeeping rate.

The random numbers of 73 groups from 1997 to 2069 are generated by MATLAB software, and each group contains 10,000 bookkeeping rates subject to the lognormal distribution $\ln (-3.283,0.356)$. Then, we take the average of each group as the fixed bookkeeping rate for the corresponding year. The investment return rate obeys the fitted Vasicek model in Formula (16), so it can also use MATLAB to 
generate its random numbers. Using MATLAB to program and substituting the above-mentioned estimated values of the number of insureds, the growth rate of working age wages, and the wages growth rate, the CBCE of UEEPPI in baseline scenario can be calculated. The calculation results are shown in Figure 3, in which the starting year (2019) is recorded as the first year and the year at the end of the forecast period is the 51st year.

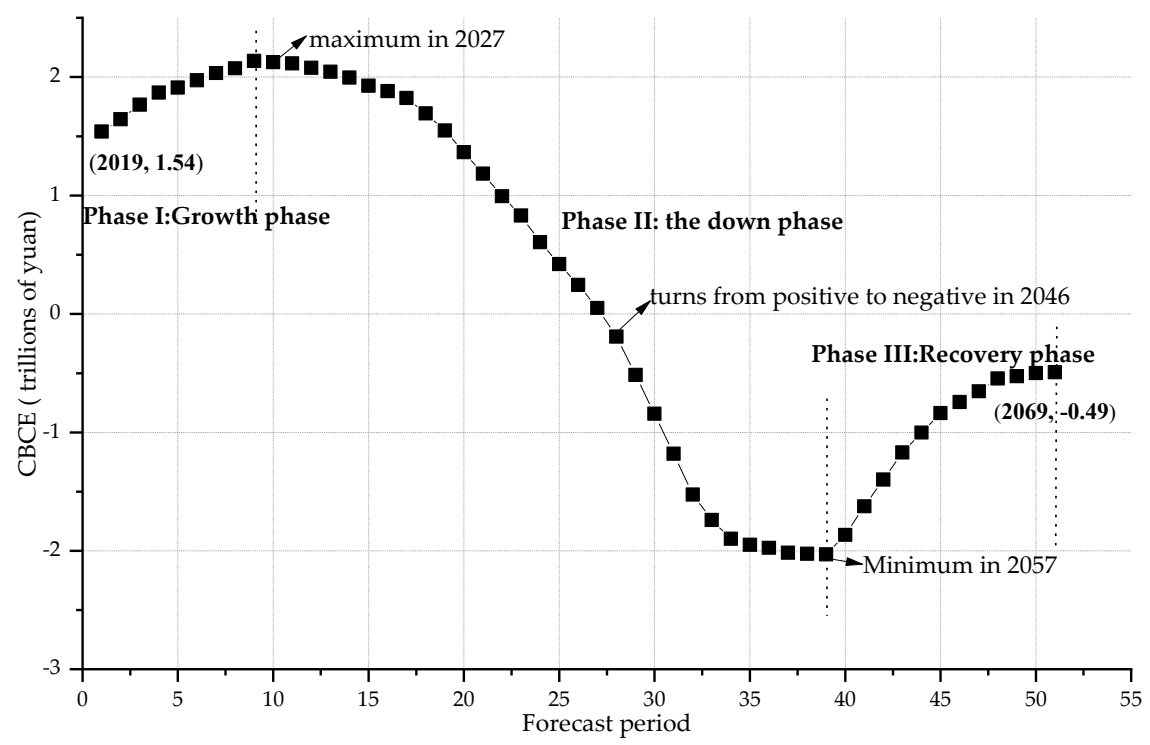

Figure 3. The calculation results of UEEPPI's current balance of contributions and expenditures (CBCE) in the baseline scenario.

The CBCE during the forecast period can be divided into three stages. Phase I is the growth stage from 2019 to 2027. The CBCE rises to a peak in 2027, which is about CNY 2.14 trillion. The rising trend at this stage is due to the contributions to individual accounts pensions increasing faster than payments out of these accounts, which may be caused by the continuous increase in the coverage of the pension plan and the strict social insurance levy imposed by the government on enterprises. Phase II is the continuous decline period from 2028 to 2057. The CBCE turns from positive to negative in 2046; thus, the gap between contributions and expenditures starts in 2046, and the gap continues to increase to CNY 2.03 trillion in 2057. This is mainly because the aging of the population in China at this stage has gradually deepened and reached a peak, and the expenditures for individual accounts pension payments exceed contributions. Phase III is the recovery stage. In 2058 and the following years, although the $\mathrm{CBCE}$ is also negative, it gradually rebounds in the direction of the CBCE being zero. This is mainly because the number of retirees who receive individual accounts pension distributions after the peak of population aging gradually decreases, and associated expenditures decrease relative to the peak period.

From the perspective of $\mathrm{CBCE}$, the UEEPPI continues to decline in phase II, during which there is a more serious gap between contributions and expenditures. However, in phase III, the UEEPPI has gradually adjusted itself, and the gap size is gradually decreasing. Therefore, the UEEPPI self-balances as it proceeds toward its future financial situation.

\subsubsection{UEEPPI's Accumulated Balance under a Fixed Bookkeeping Rate}

Further analysis of the self-balancing ability of UEEPPI under the fixed bookkeeping rate is combined with the perspective of accumulated balance. Under the extreme case that the UEEPPI was an empty account in 2018, that is, its historical accumulated balance before 2019 is zero, and the cumulative balance of the UEEPPI for each year during the forecast period is simulated by a Monte 
Carlo method. The simulation calculation was performed 10,000 times, and the calculation results are shown in Figure 4.

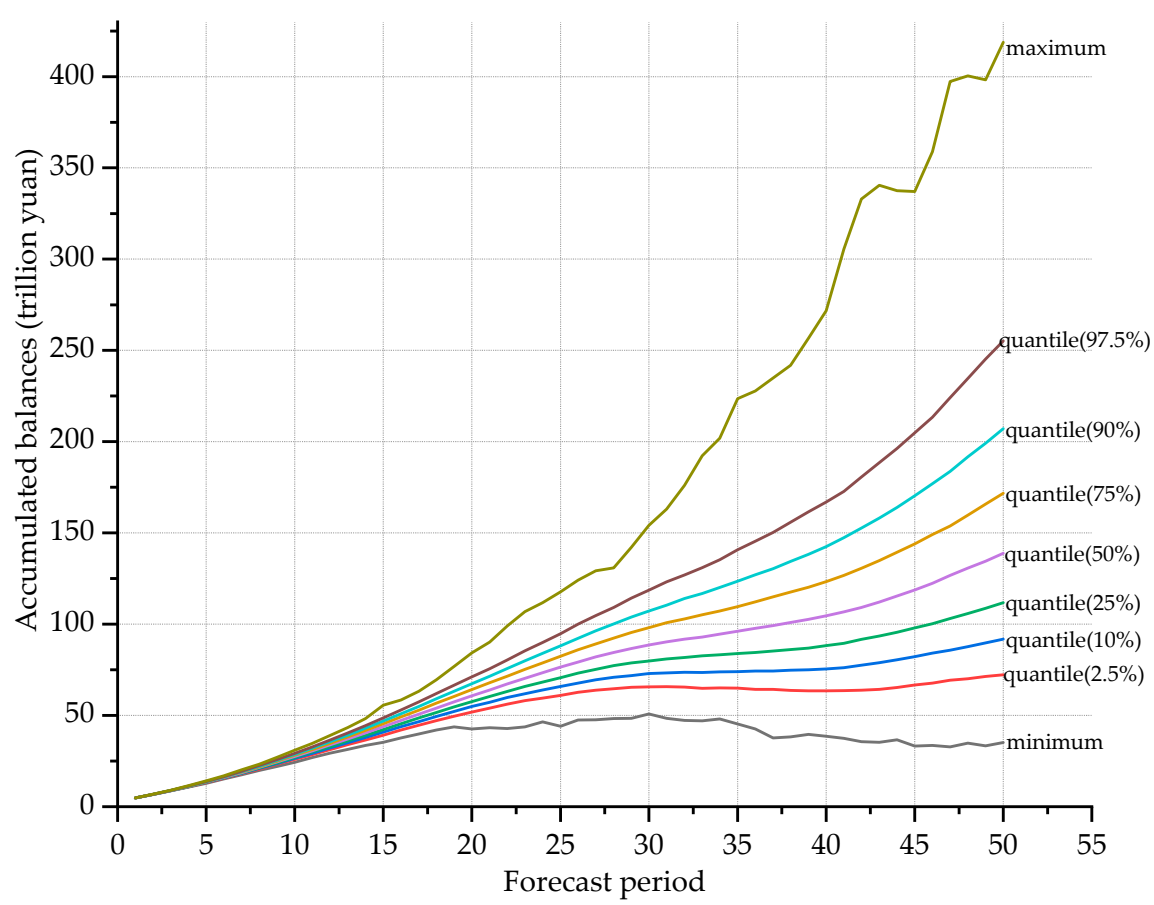

Figure 4. The calculation results of UEEPPI's accumulated balance in the baseline scenario.

As can be seen from Figure 4, even in the extreme case where UEEPPI is an empty account, its accumulated balance for each year throughout the forecast period is always positive. Moreover, it shows the trend of a gradual rise and then a decline, and then another rise, corresponding to the three phases of the CBCE. Although UEEPPI gradually leads to a gap between contributions and expenditures in the future under the trend of population aging, UEEPPI can still have a surplus after offsetting the gap solely by its own accumulated balance during the forecast period. Thus, UEEPPI reveals excellent self-balancing ability for its future financial situation.

\subsection{UEEPPI's Self-Balancing Ability under a Stochastic Bookkeeping Rate}

Assume that the Chinese government is ready to change the bookkeeping rate for the UEEPPI according to the actual situation within one year, which means that the government's bookkeeping behavior is flexible and can be used as the behavior of the stochastic bookkeeping rate. How will the self-balancing ability of UEEPPI change under this stochastic bookkeeping behavior compared with the fixed bookkeeping behavior?

Under the scenario of stochastic behavior, the bookkeeping rate is no longer taken as the average value, but is replaced by its random distribution. The Chinese government has only announced the bookkeeping rate from 2016 to 2018, and there has been no public information about it from 1997 to 2015 . Therefore, we assume that the bookkeeping rate fluctuates randomly over the entire period from 1997 to 2069. A Monte Carlo simulation method is used 10,000 times, and the calculated results of the CBCE and the cumulative balance of UEEPPI under stochastic bookkeeping rate are obtained, respectively.

5.2.1. UEEPPI's CBCE under a Stochastic Bookkeeping Rate and Comparison with the Baseline Scenario

The simulation result of UEEPPI's CBCE under the stochastic bookkeeping rate is compared with the fixed bookkeeping rate, as shown in Figure 5. 


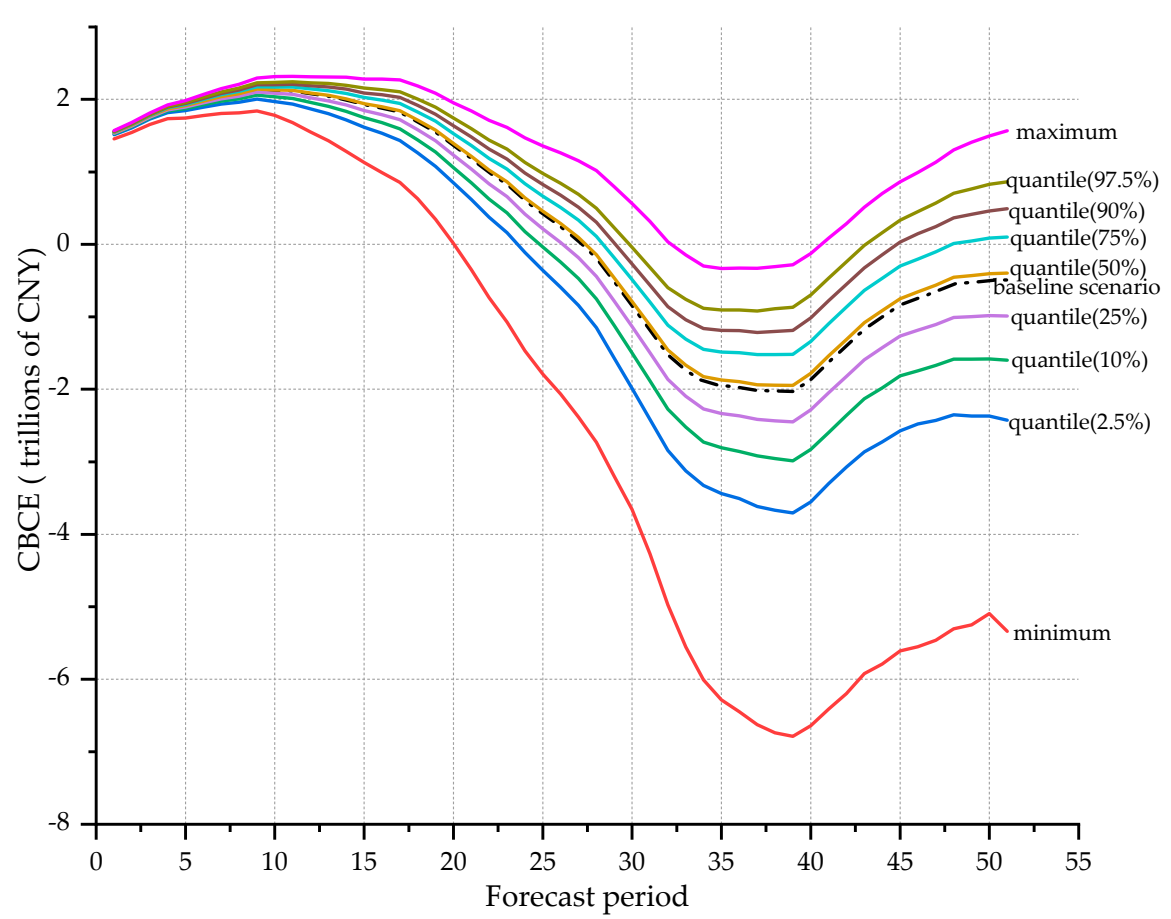

Figure 5. Comparison of the CBCE with stochastic and fixed bookkeeping rates.

We can see that the CBCE under the baseline scenario is below the $50 \%$ quantile of the stochastic scenario, indicating that the probability that the $\mathrm{CBCE}$ under the stochastic bookkeeping rate is better than the fixed bookkeeping rate exceeds $50 \%$. It shows that if the government adopts a stochastic bookkeeping rate, it can optimize the CBCE of UEEPPI, and enhance the self-balancing ability of UEEPPI compared with the baseline scenario.

We make a further comparison in the years 2046 to 2069, during which the UEEPPI experiences the gap between contributions and expenditures under the baseline scenario. Setting the frequency $P_{A}$ at $P\left\{C B C E_{t}^{\text {stochastic }} \geq C B C E_{t}^{\text {fixed }}\right\}$ and the frequency $P_{B}$ at $P\left\{C B C E_{t}^{\text {stochastic }} \geq 0\right\}, t \in[2046,2069]$, the results of $P_{A}$ and $P_{B}$ are shown in Figure 6.

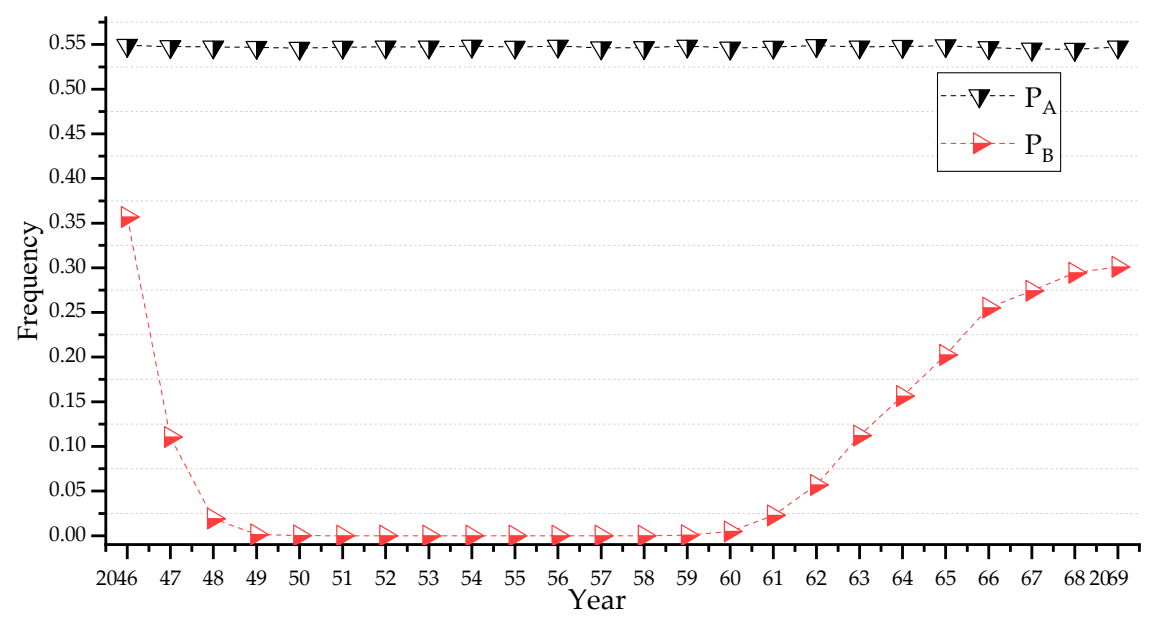

Figure 6. Frequency analysis of the CBCE.

In 2046-2069, the frequency of a gap size under a stochastic bookkeeping rate less than or equal to the fixed bookkeeping rate is stable at about 55\%. Also, the frequency PB shows the trend of declining first, then stabilizing, and then rising. It gradually decreases from a maximum of $35.69 \%$ in 2046 to near $0 \%$ in 2049 , and gradually increases to $30.10 \%$ in 2069 after hovering around zero for nearly 12 years. 
To sum up, the government's adoption of the stochastic bookkeeping rate is conducive to enhancing its ability to cope with the gap between contributions and expenditures in 2046-2069. It also indicates that the gap between contributions and expenditures in 2049-2060 is the most serious.

5.2.2. UEEPPI's Accumulated Balance under Stochastic Bookkeeping Rate and Comparison with the Baseline Scenario

The CBCE under the stochastic bookkeeping rate is in the probability region between the minimum and maximum curve in Figure 5, which increases its uncertainty compared with that under the fixed bookkeeping rate. The accumulated balance is the superposition of the uncertainty of the CBCE in each year during the forecast period, so the accumulated balance under the stochastic bookkeeping rate fluctuates more than under the fixed bookkeeping rate.

There is a simple indicator that compares the cumulative balance between the stochastic and fixed bookkeeping rate. Setting the frequency $P_{C}$ at $P\left\{A B_{t}^{\text {stochastic }} \geq \min \left(A B_{t}^{\text {fixed }}\right)\right\}, t \in[2020,2069]$, where the intervals of $A B_{t}^{\text {fixed }}$ and $A B_{t}^{\text {stochastic }}$, respectively, consist of their extremes as the upper and lower limits. Figure 7 shows the calculation result of the frequency $P_{C}$.

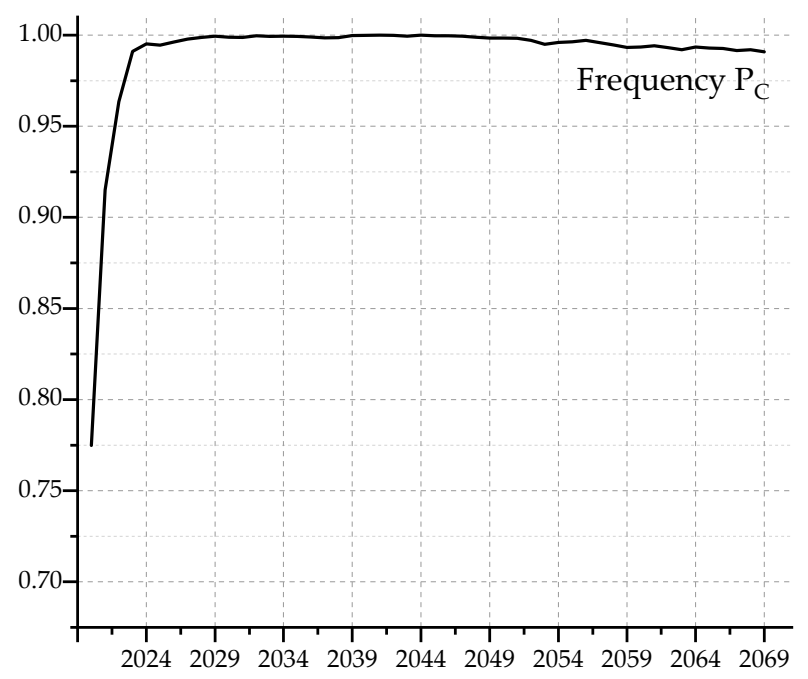

Figure 7. Comparison of the accumulated balance of the stochastic and fixed bookkeeping rates.

The accumulated balance under the stochastic bookkeeping rate is more volatile than the fixed bookkeeping rate, but the frequency $P_{C}$ is still high. Figure 7 shows that even in the year when the baseline scenario presents the gap between contributions and expenditures, the $P_{C}$ remains above $99.08 \%$.

In summary, the government's adoption of a stochastic bookkeeping rate can further improve the self-balancing ability of the UEEPPI. However, at the same time, the government should also be aware that the UEEPPI faces greater fluctuations under the stochastic bookkeeping behavior.

\subsection{Sensitivity Analysis}

In the baseline scenario of the government adopting a fixed bookkeeping rate within one year, the sensitivity analysis is conducted on the parameters that mainly affect the size of the CBCE. Sensitivity analysis is carried out by increasing the contribution wages of recruits, the contribution rate of UEEPPI, the continuous contribution rate, the wages growth rate, and the growth rate of working age wages by $1 \%$ based on their base value, respectively. The rate of change of a parameter is $\left(C B C E_{t}^{\prime}-C B C E_{t}^{\text {baseline }}\right) /\left|C B C E_{t}^{\text {baseline }}\right|$, where $C B C E_{t}^{\prime}$ refers to the change in the $C B C E$ relative to the baseline scenario after the parameter value is increased. We show the results in Figure 8. 


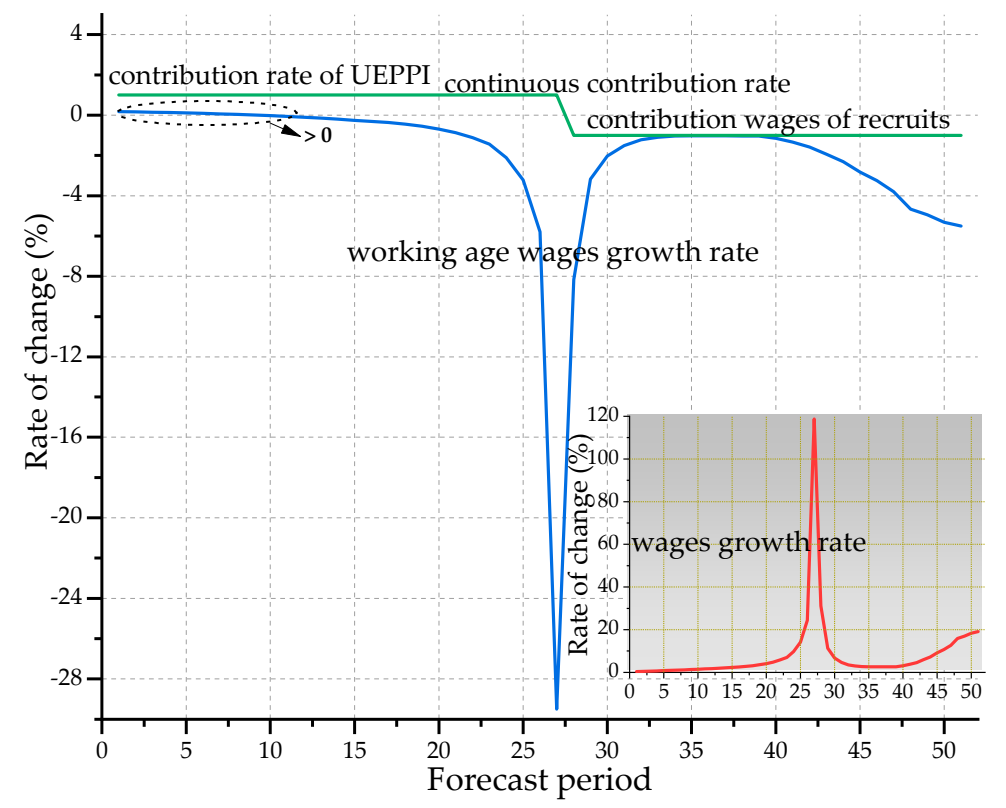

Figure 8. Sensitivity analysis.

The effects of the contribution wages of recruits, the contribution rate of UEEPPI, and the continuous contribution rate on the CBCE of UEEPPI are entirely consistent. In the formulas of pension contributions $\left(C_{t}\right)$ and pension expenditures $\left(P_{t}^{\text {life }}\right.$ and $\left.P_{t}^{\text {death }}\right)$, the contribution rate of UEEPPI $(p)$, the continuous contribution rate $(c)$, and the $S_{t, x}$ derived from the contribution wages of recruits can be separately put forward as common factors. Thus, the influences of the three parameters are mostly the same.

The effects of the three parameters promote the size of CBCE in the early stage of the forecast period, but reduce the size of CBCE in the later stage of the forecast period, thus showing a two-way effect. Since the above three parameters are involved in the pension contributions and expenditures formulas of the UEEPPI, when the parameter value is increased, the pension contributions are increased, on the one hand, and the pension expenditures for the retirees are also increased, on the other hand. When the rate of increase in pension contributions is faster than the rate of increase in pension expenditures, the $\mathrm{CBCE}$ increases compared to the baseline scenario; otherwise, it diminishes. In the early stage, when the parameter value is raised, the increase in pension contributions is faster than the increase in expenditures. With the deepening of population aging, the increase in expenditures is faster than the increase of contributions; hence, a two-way effect is apparent.

The effect of the growth rate of working age wages is similar to the contribution wages of recruits, the contribution rate of UEEPPI, and the continuous contribution rate. It also has a two-way effect. Figure 8 shows that the rate of change in the wages growth rate is greater than 0 throughout the forecast period, indicating the wage growth rate promotes the growth of $\mathrm{CBCE}$ compared to the baseline scenario. Judging the degree of influence of the above parameters on $\mathrm{CBCE}$ from the absolute average of the rate of change throughout the forecast period, we determine that the effect ranking of the wages growth rate, the growth rate of working age wages, and the contribution wages of recruits are first, second, and third, respectively. The effects of the contribution rate of UEEPPI and the continuous contribution rate are both consistent with the contribution wages of recruits, which are weak.

In summary, the increase in the wages growth rate can further enhance the self-balancing ability of UEEPPI, but the effects of the contribution wages of recruits, the contribution rate of UEEPPI, the continuous contribution rate, and the growth rate of working age wages are uncertain. 


\section{Conclusions and Policy Implications}

\subsection{Conclusions}

Under the particularly serious scenario of assuming that the accumulation amount of UEEPPI has been an "empty account," considering that both the bookkeeping rate and the investment return rate are random variables, this paper analyzes the self-balancing ability of UEEPPI in the next 50 years. We compare the impact of the Chinese government's fixed bookkeeping behavior and stochastic bookkeeping behavior on the self-balancing ability of UEEPPI. The study supports the following conclusions:

- We find that the UEEPPI presents a gap between contributions and expenditures in the baseline scenario of a fixed bookkeeping rate, but the gap will gradually decrease after 2058, and the accumulated balance of UEEPPI in each year during the entire forecast period is always greater than zero. These findings show that the UEEPPI has an excellent self-balancing ability under the fixed bookkeeping rate, which can rely on its accumulated balance to pay the pension expenditures during the entire forecast period. Therefore, we can further infer that the financial unsustainability of UEEPP funds in the future is caused by the considerable pressure of pension expenditures faced by the social pooling accounts, not by the individual accounts (UEEPPI).

- The probability that UEEPPI's CBCE is better than the fixed bookkeeping rate under the stochastic bookkeeping rate is higher than $50 \%$, and the probability that UEEPPI's cumulative balance is not worse than the fixed bookkeeping rate is still very high, exceeding $98.23 \%$. This shows that the government's adoption of a stochastic bookkeeping rate can further enhance the self-balancing ability of UEEPPI, but its accumulated balance encounters increased fluctuation.

- Sensitivity analysis finds that the wages growth rate has the greatest impact; the growth rate of working age wages follows; and the contribution wages of recruits has the weakest impact. The effects of the contribution rate of UEEPPI and the continuous contribution rate are the same as the contribution wages of recruits. Moreover, it is also found that increasing the wages growth rate can further improve the self-balancing ability of UEEPPI, while the effects of the contribution wages of recruits and the contribution rate of UEEPPI are uncertain.

\subsection{Policy Implications}

As an important part of the basic pension plan for urban employees in China, based on this study, the UEEPPI has an excellent self-balancing ability. However, the basic pension plan is confronted with the problem of financial unsustainability on the whole [18-21]. To further improve the financial sustainability of the basic pension plan, according to the above conclusions, the Chinese government can try to take the following three measures.

- The Chinese government can try to adopt a combination of fixed and stochastic bookkeeping rates for UEEPPI. In the early stage of the forecast period, the fixed bookkeeping rate can be adopted when the CBCE of UEEPPI is positive. In the late stage of the forecast period, the government may adopt a flexible bookkeeping rate when faced with the pressure of the gap between contributions and expenditures to use flexible bookkeeping rates to improve the self-balancing ability of individual accounts. When the government intends to change the bookkeeping rate in the future, it also needs to consider the rising management costs caused by a flexible bookkeeping rate and the greater fluctuation in UEEPPI's accumulated balance, to reasonably determine the number of times the bookkeeping interest rate can change within one year. By applying the two types of bookkeeping rates, the government can improve its ability to cope with the pension payment pressure caused mainly by the aging population. Thereby, the financial sustainability of the basic pension plan for urban employees can be enhanced.

- When the social pooling accounts face considerable pressure of pension expenditures in the future, the government can preferentially transfer the UEEPPI's accumulated funds to the social pooling 
accounts and then subsidize the UEEPPI in time through government fiscal expenditures or other channels. The UEEPPI has an excellent self-balancing ability for its future financial situation, and UEEPPI's accumulated balances in each year during the forecast period are positive. Thus, the government can try to properly allocate part of the accumulated funds of UEEPPI to social pooling accounts and maximize the use of the accumulated funds of the UEEPPI on the premise of ensuring the financial sustainability of the UEEPPI itself. By rationally using the cumulative funds in UEEPPI, the government can get a considerable amount of funds to meet urgent funding needs when it faces huge pension payment pressure. This measure can further guarantee the financial sustainability of the basic pension plan for urban employees.

- The government needs to respond reasonably to the pension expenditures of the 12 years during which the largest gap between contributions and expenditures exists. From the results of the sensitivity analysis, it can be seen that increasing the wages growth rate further improves the self-balancing ability of the UEEPPI. Therefore, in the face of more severe pressure on pension expenditures, the government can try to take appropriate measures to improve productivity, in order to increase the wages growth rate. This can enhance the self-balancing ability of UEEPPI, further ease the pressure of pension expenditures, and promote the sustainable development of the basic pension plan for urban employees.

\subsection{Research Limitations}

Generally, the interactions of the pension system, wages, interest rates, migration, and labor supply are considered in a general equilibrium model such as the overlapping-generations model $[50,51,54]$. In this paper, these factors are given exogenously according to the relevant literature [14-16,19-21,28]. In fact, the factors are calibrated according to average values over a comparatively long period, during which the interactions have been roughly considered. Subsequent studies can also attempt to internalize these factors to enrich the research on the financial sustainability of the Chinese pension system. Several factors could further improve this study. In the randomization of parameters, the bookkeeping rate and the investment return rate, which are closely related to UEEPPI, are considered as random variables, and other parameters are not considered. A follow-up study can further consider the wages growth rate, life table, and retirement age of insureds as random variables to explore further the self-balancing ability of UEEPPI to expand the conclusions of this study.

Author Contributions: Conceptualization, X.C. and Z.Y.; Data curation, X.C.; Investigation, X.C.; Methodology, X.C. and Z.Y.; Resources, Z.Y.; Software, X.C.; Writing—original draft, X.C.; Writing—review \& editing, X.C. and Z.Y.

Funding: This research was funded by the Research Innovation Funds from School of Insurance of Central University of Finance and Economics and the National Social Science Fund of China grant number [16BJY143].

Conflicts of Interest: The authors declare no conflict of interest.

\section{References}

1. Dorfman, M.; Holzmann, R.; O'Keefe, P.; Wang, D.W.; Sin, Y.; Hinz, R. China's Pension System: A Vision; World Bank Publications: Washington, DC, USA, 2013.

2. Billig, A.; Ménard, J.C. Actuarial balance sheets as a tool to assess the sustainability of social security pension systems. Int. Soc. Secur. Rev. 2013, 66, 31-52. [CrossRef]

3. Grech, A.G. Assessing the sustainability of pension reforms in Europe. J. Int. Comp. Soc. Policy 2013, 29, 143-162. [CrossRef]

4. $\quad$ Roseveare, D.; Leibfritz, W.; Fore, D.; Wurzel, E. Ageing Populations, Pension Systems and Government Budgets: Simulations for 20 OECD Countries; Economics Department Working Papers No. 168; The Organisation for Economic Co-operation and Development (OECD) iLibrary: Paris, France, 1996.

5. Petersen, J.H. Recent research on public pension systems. A review. Labour Econ. 1998, 5, 91-108. [CrossRef]

6. Thogersen, O. Reforming social security: Assessing the effects of alternative funding strategies. Appl. Econ. 2001, 33, 1531-1540. [CrossRef] 
7. Andersen, T.M. Increasing longevity and social security reforms-A legislative procedure approach. J. Public Econ. 2008, 92, 633-646. [CrossRef]

8. Turner, A. Population ageing: What should we worry about. Philos. Trans. R. Soc. B 2009, 364, 3009-3021. [CrossRef] [PubMed]

9. Heijdra, B.; Romp, W. Retirement, pensions, and ageing. J. Public Econ. 2009, 93, 586-604. [CrossRef]

10. Kaganovich, M.; Zilcha, I. Pay-as-you-go or funded social security? A general equilibrium comparison. J. Econ. Dyn. Control. 2012, 36, 455-467. [CrossRef]

11. The United States Social Security Administration. Available online: https://www.ssa.gov/OACT/TR/2018/ tr2018.pdf (accessed on 26 May 2019).

12. Government Actuary's Department of the British. Available online: https://www.gov.uk/government/ publications/government-actuarys-quinquennial-review-of-the-national-insurance-fund-as-at-april-2015 (accessed on 26 May 2019).

13. Wang, L.; Béland, D. Assessing the Financial Sustainability of China's Rural Pension System. Sustainability 2014, 6, 3271-3290. [CrossRef]

14. Liu, X.; Zhang, Y.; Fang, L.; Li, Y.; Pan, W. Reforming China's Pension Scheme for Urban Workers: Liquidity Gap and Policies' Effects Forecasting. Sustainability 2015, 7, 10876-10894. [CrossRef]

15. Zhao, Y.; Bai, M.; Liu, Y.; Hao, J. Quantitative Analyses of Transition Pension Liabilities and Solvency Sustainability in China. Sustainability 2017, 9, 2252. [CrossRef]

16. Wang, H.; Huang, J.; Yang, Q. Assessing the Financial Sustainability of the Pension Plan in China: The Role of Fertility Policy Adjustment and Retirement Delay. Sustainability 2019, 11, 883. [CrossRef]

17. National Bureau of Statistics of China. Available online: http://www.stats.gov.cn/tjsj/ndsj/2018/indexch.htm (accessed on 26 May 2019).

18. The World Bank. Available online: http://documents.worldbank.org/curated/en/653441468141298551/Chinapension-liabilities-and-reform-options-for-old-age-insurance (accessed on 26 May 2019).

19. Ai, H.; Zhang, Y.; Yang, C.; Wu, Y. Research on the Financial Sustainability of the Pension Insurance Pooling Account in China: Measurem. J. Financ. Econ. 2012, 38, 91-101. (In Chinese)

20. Liu, X. Study on the Financing Gap and Sustainability of China's Pension System. Chin. Ind. Econ. 2014, 9, 25-37. (In Chinese)

21. Tian, Y.; Zhao, X. A Study on the Aging Population, Postponing Retirement Age and Basic Pension Financial Sustainability. Popul. Econ. 2016, 1, 39-49. (In Chinese)

22. Guo, X. Research on the Problem of "Empty Account" in Individual Account of Basic Endowment Insurance in China. Econ. Probl. 2003, 3, 37-39. (In Chinese)

23. Lin, Y. Understanding the Long Time of Individual Account Transform from Empty to Solid. Popul. Develop. 2004, 3, 20-25. (In Chinese)

24. Zhang, Y.; Jiao, F. Research on the Problem of "Empty Account" in China's Pension Insurance Personal Account. Soc. Sci. Ningxia 2011, 3, 63-66. (In Chinese)

25. Jiang, T.; Zheng, Y. Research on Solving Empty Account and Perfecting Investment System of Individual Account. Friend. Account. 2014, 5, 22-24. (In Chinese)

26. Chen, T.; Turner, J.A. Social Security Individual Accounts in China: Toward Sustainability in Individual Account Financing. Sustainability 2014, 6, 5049-5064. [CrossRef]

27. Jin, Y. A Research on the Dynamical Balance for Personal Accounts of Endowment Insurance. Stat. Res. 2014, 31, 38-42. (In Chinese)

28. Yang, Z.; Shi, C. The Fiscal Burden and Replacement Rate of Individual Accounts for Enterprise Employee Pension. Public. Finan. Resea. 2016, 7, 80-91. (In Chinese)

29. Zhang, Y. On the IRA's Solvency in Chinese Pension System. J. Quant. Tech. Econ. 2007, 7, 126-134. (In Chinese)

30. Hu, Y.; Zheng, X. Solvency Research on Urban Employees' Individual Account in China-A Comparative Study Before and After China's Endowment Insurance System Reform. Collect. Essay Finance Econ. 2010, 3, 38-44. (In Chinese)

31. Zhang, Y. The Adjustment Mechanism of Individual Retirement Account Based on the Fund Balance. J. Quant. Tech. Econ. 2016, 33, 128-144. (In Chinese)

32. Wang, Q.; Zhou, W. The Influence of Inflation and Deflation on Personal Account Funds of Basic Pension Insurance and Countermeasures. Finan. Trade. Econ. 2007, 1, 54-56. (In Chinese) 
33. Zeng, Y.; Ren, C.; Tang, X. Will Postponing the Retirement Age Decrease the Public Subsidy of Individual Account Pension? J. Quant. Tech. Econ. 2013, 30, 81-96. (In Chinese)

34. Lee, R.D.; Carter, L.R. Modelling and Forecasting U.S. Mortality. J. Am. Stat. Assoc. 1992, 87, 659-671.

35. Lee, R.D.; Tuljapurkar, S. Stochastic Population Forecasts for the United States: Beyond High, Medium, and Low. J. Am. Stat. Assoc. 1994, 89, 1175-1189. [CrossRef]

36. Lee, R.D.; Anderson, M.W.; Tuljapurkar, S. Stochastic forecasts of the social security trust fund. SSRN Electron. J. 2003. [CrossRef]

37. Dong, M.; Guo, Y.; Yang, H. Actuarial Analysis of Implicit Pension debt in Social Pension System with Stochastic Interest Rate. Syst. Eng. 2005, 5, 55-60. (In Chinese)

38. Wang, X.; Mi, H. Clarifying Misunderstanding of Pension Replacement Rate. J. Stat. Res. 2013, 30, 52-59. (In Chinese)

39. Sun, R. The Stochastic Actuarial Models and Simulation about Retirement Annuity under Flexible Retirement System. Chin. J. Eng. Math. 2016, 33, 111-120. (In Chinese)

40. Tian, Y.; Zhao, X. Stochastic Forecast of the Financial Sustainability of Basic Pension in China. Sustainability 2016, 8, 46. [CrossRef]

41. Zheng, S.; Liao, P. Actuarial model for urban public pension fund in China. Syst. Eng. Theory Pract. 2017, 37, 2222-2230.

42. Zhao, Y.; Bai, M.; Feng, P.; Zhu, M. Stochastic Assessments of Urban Employees' Pension Plan of China. Sustainability 2018, 10, 1028. [CrossRef]

43. Yang, Z.; Xu, D. Fiscal Burden of Chinese State Organ and Institution Employees' Pooling Account Pension. Wuhan. Univ. J. Soc. Sci. 2017, 70, 52-65. (In Chinese)

44. Vasicek, O.A. An equilibrium characterization of the term structure. J. Financ. Econ. 1997, 5, 177-188. [CrossRef]

45. Xie, C.; Wu, X. An Empirical Analysis of the Interest Rate Behavior in China's Monetary Market Using the Vasicek and CIR Models. Chin. J. Manag. Sci. 2002, 3, 23-26. (In Chinese)

46. Zhao, J.; Guo, S.; Luo, C. A study on life insurance product pricing under Vasicek Model. Insur. Stud. 2008, 7, 44-46. (In Chinese)

47. Brennan, M.J.; Schwartz, E.S. An Equilibrium Model of Bond Pricing and a Test of Market Efficiency. J. Financ. Quant. Anal. 1982, 17, 301-329. [CrossRef]

48. Sanders, A.B.; Unal, H. On the Intertemporal Behavior of the Short-Term Rate of Interest. J. Financ. Quant. Anal. 1988, 23, 417-423. [CrossRef]

49. Zheng, W.; Lin, S.; Chen, K. Characteristics and Trend of Population Aging in China and Its Potential Impact on Economic Growth. J. Quant. Tech. Econ. 2014, 31, 3-20. (In Chinese)

50. Breyer, F.; Kolmar, M. Are national pension systems efficient if labor is (im)perfectly mobile. J. Public Econ. 2002, 83, 347-374. [CrossRef]

51. Fedotenkov, I.; Meijdam, L. Crisis and Pension System Design in the EU: Intergenerational Redistribution and International Spillover Effects via Factor Mobility; SSRN Working Paper; Department of Economics, CentER, and Netspar, Tilburg University: Tilburg, The Netherlands, 2011.

52. Wang, J.; Ge, Y. Population Trends in China under the Universal Two-Child Policy. Popul. Res. 2016, 40, 3-21. (In Chinese)

53. Ministry of Human Resources and Social Security Business Management Center. Available online: http: //www.mohrss.gov.cn/gkml/shbx/shbxjb/201802/t20180206_288037.html (accessed on 26 May 2019).

54. Bucciol, A.; Cavalli, L.; Fedotenkov, I.; Pertile, P.; Polin, V.; Sartor, N.; Sommacal, A. A large scale OLG model for the analysis of the redistributive effects of policy reforms. Eur. J. Polit. Econ. 2017, 48, 104-127. [CrossRef]

(C) 2019 by the authors. Licensee MDPI, Basel, Switzerland. This article is an open access article distributed under the terms and conditions of the Creative Commons Attribution (CC BY) license (http://creativecommons.org/licenses/by/4.0/). 